Artigo recebido em:

06.05.2018

Aprovado em: 15.07.2018

Thays Assunção Reis

Mestre em Jornalismo pela Universidade

Estadual de Ponta Grossa

(UEPG). Doutoranda pelo Programa de Pós-Graduação em Comunicação da

Universidade do Estado do Rio de Janeiro (UERJ).

E-mail: thays.jornalista@ gmail.com

Estudos em Jornalismo e Mídia Vol. 15 No 1 Janeiro a Junho de 2018 ISSNe 1984-6924

\section{Jornalismo Regional: uma leitura a partir dos critérios de noticiabilidade do jornal $O$ Progresso}

Thays Assunção Reis

\section{Resumo}

O jornalismo regional pressupõe uma prática que extrapola os limites territoriais das sedes dos seus veículos, abastecendo com notícias outras localidades. Com base nisso, este artigo busca identificar quais critérios de noticiabilidade, a partir de Silva (2014a), são acionados por uma publicação regional para cobrir as localidades próximas ou do mesmo estado. Para alcançar este propósito, optou-se por uma metodologia mista com o emprego de revisão bibliográfica e análise de conteúdo das matérias publicadas no jornal O Progresso, diário produzido em Imperatriz (MA) durante o mês de outubro de 2017, a fim de mapear as notícias dos municípios da redondeza e sistematizar os critérios de noticiabilidade presentes nos textos. Foram identificadas notícias de 45 cidades, tanto do Maranhão (Estado sede do veículo), quanto do Tocantins. Verificou-se que proximidade, justiça e governo são os principais critérios de noticiabilidade presentes na cobertura regional.

Palavras-chaves: Critérios de Noticiabilidade. Jornalismo Regional. O Progresso. Maranhão.

Regional Journalism: a perspective based on newsworthiness criteria of the newspaper $O$ Progresso

\section{Abstract}

Regional journalism presupposes a practice that goes beyond the territorial limits of its vehicles, fueling other locations with news. Based on this, the article seeks to identify which criteria of newsworthiness, according to Silva (2014a), are used by a regional publication to cover the localities nearby or the same state. To achieve this purpose, a mixed methodology was chosen with the use of bibliographical review and content analysis of the articles published by $O$ Progresso, a daily newspaper produced in Imperatriz (MA), during the month of October, 2017, in order to map the news from the surrounding municipalities and to systematize the newsworthiness criteria present in the texts. News from 45 cities, both from Maranhão (home state of the media) and from Tocantins, were identified. It was also observed that proximity, justice and government are the main criteria for news in the regional coverage.

Keywords: Newsworthiness criteria. Regional Journalism. O Progresso. Maranhão. 


\section{Introdução}

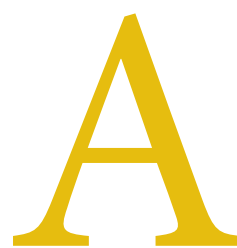

s singularidades regionais e locais da prática jornalística são um assunto que merece atenção, ganhando força no campo do jornalismo brasileiro. Situação oriunda da desconcentração dos meios de comunicação de massa fora do eixo da mídia nacional, situado na região Sudeste/Centro-Oeste, entre os estados de São Paulo, Rio de Janeiro e o Distrito Federal (FADUL; GOBBI, 2006). Neste sentido, tornou-se claro para os pesquisadores que o jornalismo não apresenta o mesmo padrão em todos os lugares, mas ganha contornos da realidade que os rodeia.

A produção noticiosa seguindo a organização, agendamentos, rotinas e processos decorrentes da demarcação territorial onde estão localizadas as empresas jornalísticas ampliaram as investigações sobre as mídias no interior do Brasil. Desse modo, as regionalidades passaram a ser estudadas "ora como (contra) exemplo a ser seguido pelos modelos industriais de produção noticiosa, ora como demanda informativa a ser explorada ou campo de atuação" (GADINI; SCHOENHERR, 2016).

Ampliando esta discussão, Deolindo (2016) agrupa os estudos brasileiros sobre as mídias e as áreas geográficas nos seguintes eixos temáticos: a) histórica (trata da trajetória de jornais locais e regionais), b) representações sociais (pesquisas que analisam discursos, enquadramentos e conteúdos que reforçam a identidade regional/comunitária), c) conceitual (sobre as especificidades e natureza do jornalismo regional, sua distinção frente ao comunitário e suas aproximações com a grande mídia), d) inventário (identifica, enumera, registra e analisa mídias já extintas ou ainda em funcionamento em determinadas regiões), e) crítica (trata das relações de propriedade e a vinculações da mídia regional com outras instituições, como a política e a econômica).

Além de objeto de pesquisa, a mídia regional tem sido alvo nos últimos anos do interesse de órgãos públicos e entidades de classe da área de comunicação do nosso país, que vem investindo, de forma mais consolidada, no mapeamento dos meios de comunicação no Brasil. Temos o exemplo do Instituto Brasileiro de Geografia e Estatística (IBGE) que, em 2008, publicou o estudo "Regiões de Influência das Cidades" com dados das redes de televisão, domínios de internet e origem dos jornais vendidos no país. Além disso, a instituição lançou em 2010 o "Atlas Nacional do Brasil Milton Santos" que também disponibiliza informações sobre as emissoras de rádio, publicidade, TV aberta e digital, domínio da internet e telefonia celular.

Em 2017, surgiu uma das principais iniciativas sobre mídia regional - o Atlas de Notícia. Um projeto desenvolvido pelo Instituto para o Desenvolvimento do Jornalismo (Projor) em parceria com a Volt Data Lab ${ }^{1}$, que busca mapear os veículos produtores de notícias no Brasil. Em sua primeira etapa, o projeto identificou 5.354 veículos - entre jornais impressos e sites -, em 1.125 cidades das 27 unidades federativas. O estudo também constatou que 4,5 mil municípios, representando mais de 70 milhões de habitantes, não possuem nenhum veículo no segmento escrito e digital, denominando-os de "desertos de notícias".

Baseado nesses dados, que funcionam como um sobrevoo para termos uma visão ampla do jornalismo local e regional brasileiro, verificamos que das $268^{2}$ cidades de porte médio do país (cuja população situa-se entre 100 e 500 mil habitantes), 221 possuem pelo menos um jornal impresso em funcionamento. Deste número, o presente artigo aborda, especificamente, o jornal O Progresso, diário produzido na cidade média de Imperatriz ${ }^{3}$ (interior do Maranhão). O intuito deste trabalho é verificar como este impresso, por meio da sua produção de conteúdo, relaciona-se com as cidades próximas, uma vez que a publicação apresenta um alcance regional.
${ }^{1}$ Agência independente de jornalismo e de pesquisas que produz análises, reportagens, investigações, relatórios e levantamentos para redações, ONGs, projetos de mídia, empresas de comunicação e terceiro setor no Brasil e exterior. Site: https://www. voltdata.infol

${ }^{2}$ Número encontrado a partir da estimativa da população residente nos municípios brasileiros com data de referência em 01 de julho de 2017 publicado pelo IBGE.

${ }^{3}$ Segunda maior cidade do Maranhão, com uma população de 254.569 mil habitantes, segundo IBGE (2017). Fica localizada no sudoeste do Estado, próxima ao Pará e Tocantins. 
Como procedimento metodológico foi desenvolvido, em primeiro lugar, uma revisão da literatura especializada em jornalismo regional/local e critérios de noticiabilidade para dar suporte ao marco teórico construído antes do estudo das notícias. Em seguida, foi realizada a análise de conteúdo (BARDIN, 2016) nas matérias do Progresso durante o mês outubro de 2017, totalizando 20 edições. Segundo Herscovitz (2008, p. 123), este método é frequentemente empregado "para identificar tendências e modelos de análise de critérios de noticiabilidade, enquadramentos e agendamentos. Serve também para descrever e classificar produtos, gêneros e formatos jornalísticos", entre outros aspectos.

As matérias foram analisadas a partir de três categorias: a) editoria; b) município; e c) critérios de noticiabilidade. A coleta desse último grupo norteou-se pela tabela operacional de Gislene Silva (2014a), constituída de 12 grandes atributos: Impacto (compreende número de pessoas afetadas ou envolvidas no fato, e grande quantia de dinheiro); Proeminência (engloba notoriedade, celebridades, posição hierárquica, elite e sucesso/herói); Conflito (diz respeito a acontecimentos sobre guerra, rivalidade, disputa, briga, greve e reivindicação); Tragédia/Drama (refere-se à catástrofe, acidente, risco de morte e morte, violência/crime, suspense, emoção e interesse humano); Proximidade (abrange os níveis geográfico e cultural); Raridade (remete a acontecimentos incomuns, originais e inusitados); Surpresa (relaciona-se a acontecimentos inesperados); Governo (contempla fatos de interesse nacional, decisões/medidas, inaugurações, eleições, viagens e pronunciamentos); Polêmica (são fatos controversos e escândalos); Justiça (acontecimentos envolvendo julgamentos, denúncias, investigações, apreensões, decisões judiciais e crimes); Entretenimento/Curiosidade (envolve fatos ligados à aventura, divertimento, esporte e comemoração) e Conhecimento/Cultura (refere-se a descobertas, invenções, pesquisas, progresso, atividades/valores culturais e religião).

Para efeito do estudo foram consideradas as matérias que, mesmo não sendo veiculadas diretamente pelas editoriais regional ou Tocantins, também tratavam de atividades e acontecimentos dos municípios da microrregião do Imperatriz, das cidades tocantinenses que estão localizadas nas redondezas ou de outras cidades do Maranhão.

\section{Jornalismo regional: em busca de um conceito}

Uma das principais questões enfrentadas pelos estudos de jornalismo regional diz respeito à sua própria definição, que se confunde com a de jornalismo do interior, local ou mesmo comunitário, devido a serem "práticas jornalísticas marcadas por uma maior proximidade geográfica em relação aos fatos que reportam, com os leitores que privilegiam e com as fontes às quais dão voz" (AGUIAR, 2016, p. 17). Por isso, é pertinente apontar algumas perspectivas que perpassam a temática para refletir sobre o quê e como se desenvolve o jornalismo regional, em torno dos mais diversos suportes comunicacionais.

A maioria dos esforços para pensar o jornalismo regional brasileiro está atrelada à classificação e/ou diferenciação dos veículos no país. Uma das primeiras tentativas desenvolvidas nesse sentido foi forjada pelo geógrafo Milton Santos, em 1955, durante o IV Congresso Nacional de Jornalistas, em Belo Horizonte. Nesse encontro, ele apresentou uma proposta de classificação funcional dos jornais para ser utilizada na construção futura de um "mapa jornalístico no Brasil”. Essa proposição delimitou, com base no contexto, quatro categorias de jornais no país: a) nacional (circula na capital da República e em São Paulo, nas capitais estaduais e em camadas restritas das cidades servidas por linhas aéreas diárias); b) estadual (cobre a superfície do estado respectivo. Sua função regional é, porém, tanto 
mais reduzida quanto mais desenvolvida a economia provincial e a sua rede de transportes); c) regional (circula em sua área respectiva, sofrendo nas bordas a concorrência do jornal da região vizinha), e d) local (atende a interesses do lugar onde atua e não raro a problemas de natureza efêmera, animando-se ao sopro de paixões momentâneas, que marcam geralmente o seu tempo de vida ou renascimento) (SANTOS, 1955 [2007]).

Nos estudos de comunicação, uma classificação parecida e recente, porém voltada para os jornais do interior, é apresentada por Wilson da Costa Bueno, em um dos capítulos da coletânea Imprensa do Interior: conceitos e contextos, organizada por Francisco de Assis (2013). Conforme Bueno (2013), existem três tipos ideais de jornais: o jornal local "quase artesanal", o jornal local estruturado e o jornal regional. Os dois primeiros têm como limite de "circulação a cidade em que mantém a sua sede, e o terceiro objetiva exercer sua influência numa determinada região, abarcando, portanto, com sua circulação e cobertura, algumas cidades ou municípios" (BUENO, 2013, p. 45-46).

A perspectiva de Bueno (2013) nos faz entender que o jornalismo regional ocorre em um cenário maior - o interior. Esse ambiente, conforme Assis (2013, p. 2), abrange "as cidades de médio e pequeno porte, em oposição às suas capitais e às cidades que integram as regiões metropolitanas". Neste sentido, o jornalismo praticado no interior assume uma atuação diferenciada da "grande imprensa", "tanto no que diz respeito à circulação quanto às próprias condições de sua produção, quase sempre marcada por limitações (financeiras, de pessoal treinado, de equipamentos, de acesso, etc.)" (ASSIS, 2013, p. 5).

De outra forma, Dornelles (2004) afirma que o jornalismo do interior é muito mais comportamental do que estrutural, sendo guiado por uma "política de vizinhança, a solidariedade, o coletivismo, os valores, a moral, a fé religiosa, o respeito humano e a cultura de pequenas populações" (DORNELLES, 2004, p. 132). Além disso, a filosofia editorial dos jornais é comunitária, ou seja, tem como objetivo central a produção de matérias que atendam aos anseios e reivindicações da comunidade.

Por sua vez, Deolindo (2013, p. 7-8) considera que o jornalismo regional preenche a lacuna de informação deixada pela prática jornalística nacional e estadual referente à multiplicidade de acontecimentos que ocorrem no país. Os jornais regionais e locais, juntamente com os portais de notícias regionais, "publicam notícias de interesse direto e próximo da comunidade, ao mesmo tempo em que reproduzem informações dos grandes centros para manter o público informado do que se passa [lá fora]".

A partir das referências acima, compreendemos que o jornalismo regional constitui-se como uma prática, desenvolvida por cidades de grande e médio porte, que pode extrapolar os limites territoriais da sede dos seus veículos e atender noticiosamente centros urbanos menores que não dispõem de meios de comunicação tradicionais ou outros canais de informação para se informar acerca do próprio cotidiano ou para realizar suas solicitações.

\section{Critérios de noticiabilidade: conceitos e aproximações da notícia regional}

Ao abordar o jornalismo regional e suas especificidades, vários autores (ALSINA, 2009; DORNELLES, 2010; CAMPONEZ, 2012; FERNANDES, 2013) apontam a proximidade como o critério distintivo da prática jornalística desenvolvida fora dos grandes centros urbanos. No entanto, antes de enfrentar este tema, temos de ter clareza sobre os critérios que os jornalistas utilizam para identificar se um evento é noticiável. 
Uma das principais questões levantadas pelos estudos que têm o jornalismo como objeto de reflexão é: O que faz um acontecimento, em detrimento a outro, receber o status de notícia? As tentativas para responder a este questionamento, segundo Marcos Paulo Silva (2014b), provêm das formulações teóricas contidas nas Teorias do Jornalismo.

O primeiro grupo de teorias apontado por Silva (2014b), com base nas formulações do sociólogo Herbert Gans (2004), é centrado na figura dos jornalistas, e sustenta-se na premissa de que a formatação do conteúdo noticioso resulta do julgamento subjetivo dos jornalistas [ex: teoria do gatekeeping]. O segundo grupo teórico enfatiza as rotinas de produção das organizações noticiosas. O terceiro conjunto fundamenta-se na própria natureza dos eventos noticiáveis [ex: teoria do espelho]. E o quarto grupo de teorias concentra-se no processo de seleção noticiosa a partir de forças oriundas do exterior das organizações jornalísticas.

Todas as teorias apresentadas acima partem do entendimento que a seleção das notícias é guiada por determinados parâmetros, são os chamados critérios de noticiabilidade. De acordo com Traquina, os critérios de noticiabilidade "são o conjunto de valores-notícia que determinam se um acontecimento, ou assunto, é susceptível de se tornar notícia” (TRAQUINA, 2008, p. 63).

Para este autor, os valores-notícia dividem-se em dois grandes grupos: seleção e construção. Posteriormente, ele divide os critérios de seleção em substantivos e contextuais, agrupando-os da seguinte forma: Critérios substantivos: morte, notoriedade, proximidade, relevância, novidade, tempo, notabilidade, inesperado, conflito ou controvérsia e infração. Critérios contextuais: disponibilidade, equilíbrio, visualidade, concorrência e dia noticioso. E os valores-notícia de construção são distribuídos em: simplificação, amplificação, relevância, personalização e dramatização.

Após fazer essas ponderações sobre os critérios de noticiabilidade, vamos à proximidade. Conforme Fernandes (2013), ela é um dos critérios de noticiabilidade mais fortes na produção jornalística do interior, visto que a força integrativa e identitária dos veículos das cidades de pequeno e médio porte estão na notícia de proximidade. $\mathrm{O}$ autor explica que:

Para um profissional atuante no jornal do interior, a proximidade, associada à atualidade, prevalece no momento de seleção de uma notícia. Depois se agregam outros elementos, como importância, tamanho etc. Uma notícia sobre alguma medida tomada pelo governo federal pode ser atual, importante e se enquadrar nas medidas disponíveis na página, mas será descartada se não tiver um elemento de interesse estritamente local (FERNANDES, 2013, p. 115).

Dornelles (2010) compartilha do mesmo entendimento ao afirmar que a proximidade é um dos elementos da notícia mais importantes para a imprensa do interior. A proximidade "trata de comunicar conteúdos considerados pertinentes aos seus leitores com o objetivo de conseguir a fidelização dos públicos" (DORNELLES, 2010, p. 239). É por isso que os periódicos interioranos priorizam em suas páginas as informações locais que despertam rapidamente o interesse dos moradores que residem na cidade-sede do veículo.

Sob o mesmo ponto de vista, Alsina (2009) comenta que a proximidade é o grande potencial comunicativo dos meios locais. Por meio dela, os veículos transmitem notícias que os outros meios de maior cobertura, como os nacionais ou estaduais, quase não veiculam. Dessa forma, os cidadãos das cidades menores acabam produzindo um maior envolvimento com estas notícias, e recorrendo à "grande mídia" apenas quando acontecem desgraças naturais, por exemplo.

Por outro lado, Carlos Camponez (2012) defende a proximidade como uma questão basilar do jornalismo e não uma exclusividade da imprensa local-regional, já 
que todos os veículos se esforçam para comunicar conteúdos relevantes para leitores e definem estratégias empresariais com o intuito de conseguir a fidelização de seus públicos. No Brasil, por exemplo, os jornais das grandes metrópoles estão ampliando a divulgação de fatos locais por meio dos cadernos regionais ou de bairros.

\section{A produção regional do jornal $O$ Progresso}

Desde seu início, em 3 de maio de 1970, O Progresso nasceu com a proposta, encabeçada pelo empresário José Matos Vieira e o jornalista Jurivê de Macedo, de ser uma publicação regional, destinada a responder às demandas de informação da Região Tocantina ${ }^{4}$. Atualmente, o impresso circula em Imperatriz e mais oito municípios da sua microrregião $0^{5}$ (Açailândia, Carolina, Porto Franco, Estreito, Balsas, Ribamar Fiquene, Governador Edson Lobão e Cidelândia), além de diversas localidades do norte do Tocantins.

O Progresso é publicado de terça-feira a sábado com 16 páginas divididas em dois cadernos e oito editorias: "Política", "Polícia", "Cidade", "Regional”, "Esporte", "Geral", "Justiça" e "Tocantins". Na edição de domingo, a publicação alcança as 30 páginas devido à presença do suplemento literário "Extra" e do "Caderno de Domingo". O impresso apresenta uma tiragem diária de 5,3 mil exemplares, segundo informações disponibilizadas no site do veículo.

Mostrando os critérios de noticiabilidade considerados pelo O Progresso para pautar as cidades localizadas no entorno de Imperatriz ou no Maranhão, o levantamento realizado nas 20 edições do mês de outubro de 2017 identificou 135 matérias sobre acontecimentos de outras cidades. Deste número, foram encontradas referências a 45 localidades, sendo as mais frequentes: São Luís-MA (39), Araguaína-TO (23), João Lisboa-MA (5), Palmas - TO (5), Açailândia-MA (4), Bacabal-MA (4), Balsas-MA (4) e Governador Edson Lobão-MA (3).

Percebe-se que as notícias de São Luís ultrapassaram as das cidades vizinhas de Imperatriz em virtude da localidade ser a sede do poder administrativo do estado, o que faz com as decisões e medidas do governo estadual reverberem no território imperatrizense e interior do Maranhão. Além deste aspecto, os campeonatos e competições estaduais fazem com que a capital maranhense seja alvo da atenção dos veículos do interior.

As cidades do Tocantins, como Araguaína e Palmas, acabam tornando-se recorrentes no impresso devido à editoria intitulada "Tocantins", destinada a assuntos desse Estado. O mesmo não se aplica às cidades vizinhas de Imperatriz (João Lisboa, Açailândia e Governador Edson Lobão), onde circula o periódico. Essas e outras localidades inseridas na área de comercialização do jornal apresentaram uma baixa presença nas edições consultadas. Infere-se, portanto, um consumo inexpressivo da publicação nesses lugares.
${ }^{4}$ Compreende as cidades do sudoeste do Maranhão banhadas pelo Rio Tocantins.

${ }^{5}$ A microrregião de Imperatriz pertence à mesorregião do oeste do Maranhão e é formada por dezesseis municípios: Açailândia, Amarante do Maranhão, Buritirana, Cidelândia, Davinópolis, Governador Edison Lobão, Imperatriz, Itinga do Maranhão, João Lisboa, Lajeado Novo, Montes Altos, Ribamar Fiquene, São Francisco do Brejão, São Pedro da Água Branca, Senador La Rocque, Vila Nova dos Martírios. 


\section{MAPA 1 - Regionalização do jornal O Progresso}

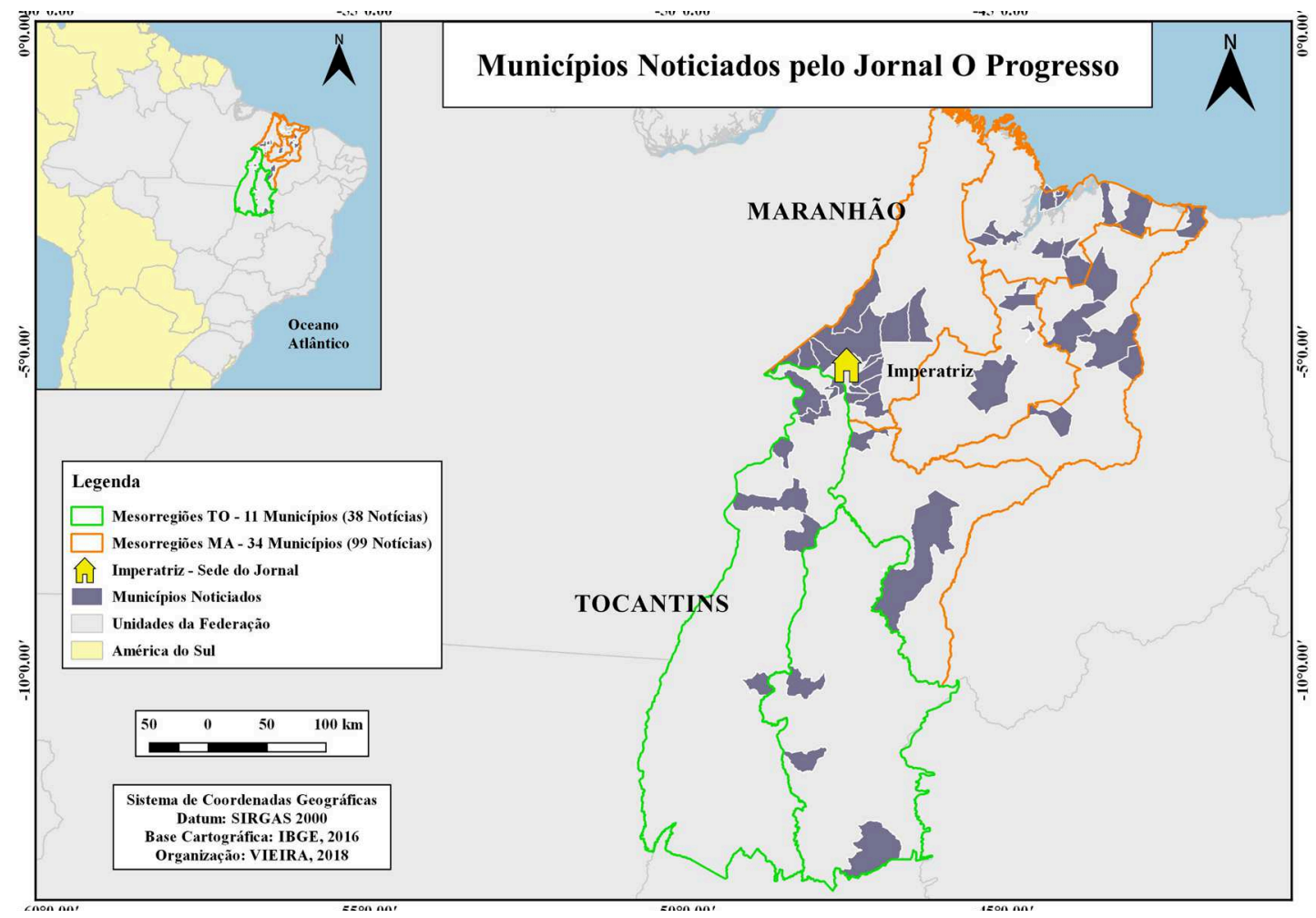

Fonte: Autora / Elaboração: Camila Vieira

Uma das possíveis explicações para esta situação pode estar no fato de que os acontecimentos do cotidiano dessas cidades podem perpassar outros canais. "Os mass media não é nossa única fonte de informação aos assuntos públicos. A experiência pessoal, que inclui conversações com nossa família, amigos e colegas de trabalho, também nos informa sobre muitos temas" (MCCOMBS, 2009, p. 99).

Em seguida, constatou-se que a maioria das matérias regionais (37) está concentrada na editoria de "Polícia", ao passo que o espaço reservado para cobrir as cidades próximas (editoria "Regional") registrou apenas sete ocorrências. As outras editorias que abriram espaço para as notícias regionais foram: "Tocantins" (34), "Política" (22), "Esporte” (16), "Justiça" (14), "Cidade" (3), "Publicações" (1) e "Regional Itz Agro" (1), segundo revela o Gráfico 1.

Vale destacar que a editoria "Regional" é publicada, geralmente, apenas uma vez por semana. Já a página voltada para assuntos do "Tocantins" é lançada duas vezes na semana, às terças e quintas-feiras, o que explica o número expressivo de notícias regionais nessa editoria. Essa mesma lógica pode ser usada nas editorias de "Política", "Esporte" e "Justiça", que são espaços diários no Progresso.

\section{GRÁFICO 1 - Distribuição das matérias regionais por editoria}

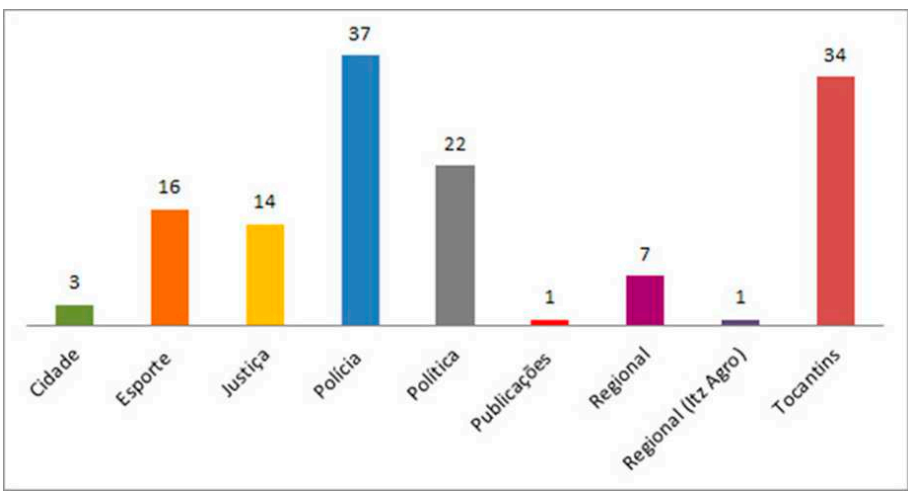


Ainda chama atenção nesse aspecto o fato das notícias contidas nas editorias serem, em sua maioria, textos sobre as ações das prefeituras municipais ou do governo do estado. Tal situação faz com que o impresso deixe de ser um veículo a serviço dos interesses da população para se tornar "um veículo dos órgãos públicos, com propagandas disfarçadas de notícias relevantes para a população local e regional, quando, na verdade, deveriam possuir o crivo jornalístico" (ALVES; CUNHA, 2014, p. 6).

As informações do levantamento confirmam a proximidade como um dos principais critérios de noticiabilidade acionados pela produção jornalística regional, com a presença de 53 ocorrências nas matérias do jornal O Progresso. Em seguida apareceram Justiça (51), Governo (31), Entretenimento/Curiosidade (18), Proeminência (18), Impacto (13), Tragédia/Drama (11), Polêmica (7) e Conflito (3), como pode ser visto no Gráfico 2.

Durante a análise do material foi possível encontrar mais de um critério de noticiabilidade em uma mesma notícia, sendo a proximidade geográfica a mais recorrente. Esse atributo costumava aparecer associado aos critérios de "Governo", "Justiça" ou "Tragédia/Drama" em publicações relacionadas aos municípios próximos de Imperatriz. É o caso da notícia "Homem é encontrado Morto em Araguaína" (O PROGRESSO, 10 de outubro de 2017, C2, p. 2) que apresenta como valor-notícia principal a "Tragédia/Drama" por se tratar do assassinato de um jovem de 23 anos dentro da sua própria casa. Associado a esse critério, infere-se que a proximidade geográfica contribuiu para que o acontecimento fosse elevado ao status de notícia pelo jornal O Progresso, visto que Araguaína fica a $247 \mathrm{~km}$ do território imperatrizense, cerca de $3 \mathrm{~h} 30 \mathrm{~min}$ de carro. Além do mais, esse município apresenta uma proximidade "temática" (ALSINA, 2009) com Imperatriz devido às afinidades econômicas enquanto entreposto comercial e de serviços para a região.

\section{GRÁFICO 2 - Critérios de noticiabilidade das notícias regionais}

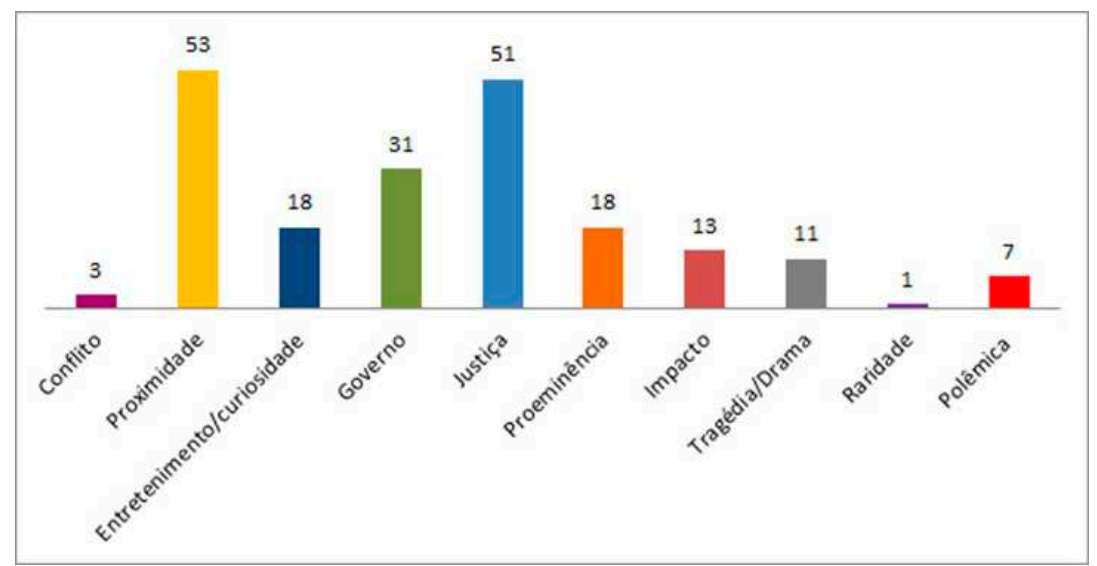

Fonte: elaboração da autora

Outro exemplo da presença do critério de proximidade é a matéria "Criada a Associação Comercial de Governador Edson Lobão" (O PROGRESSO, 06 de outubro de 2017, C2, p. 7) que abordava a fundação da entidade representativa da classe dos empresários do município localizado a $30 \mathrm{~km}$ de Imperatriz. Neste caso, verificou-se que a proximidade geográfica e a proeminência dos atores superaram a atualidade do fato, visto que o mesmo já havia acontecido há mais de uma semana da data de publicação no impresso.

No caso dos centros urbanos distantes de Imperatriz como, por exemplo, São Luís Timon, Codó, Barreirinhas, Caxias no Maranhão ou mesmo Palmas no Tocantins, os critérios de noticiabilidade que se sobressaíram foram "Justiça" e 
"Governo" em virtude da proximidade geográfica pressupor "um maior envolvimento, com o centro dele mesmo, que diminui na medida em que esse círculo aumenta" (ALSINA, 2009, p. 150).

O critério de justiça foi encontrado, basicamente, nas publicações de apreensões, decisões judiciais ou crimes. É o caso da notícia publicada no dia 21 de outubro de 2017 sobre a apreensão de 200 quilos de maconha no município de São José do Ribamar (pertencente à região metropolitana de São Luís). Essa referência indica que os fatos promotores de "ruptura" são mais propícios de virarem notícia, e assim, fazerem com que outras cidades, fora Imperatriz, sejam pautadas pelo Progresso. "[...] A vida cotidiana gira em torno de uma rotina previsível, mas uma quebra dessa rotina por meio de um fator imprevisível ou incidental gerará noticiabilidade" (FRANCISCATO, 2014, p. 102).

Interessante destacar que em alguns casos o critério de justiça aparecia associado ao de polêmica, como aconteceu na notícia "Ex-prefeita de Bom Jardim é presa pela polícia civil em São Luís” (O PROGRESSO, 25 de outubro de 2017, C1, p.7). O texto trata do escândalo do crime de improbidade administrativa envolvendo Lidiane Leite, ex-prefeita da cidade de Bom Jardim no interior do Maranhão.

No caso do critério de governo, sua presença foi registrada em notícias de inaugurações de obras, pronunciamentos ou outras atividades promovidas pelos governos municipais ou estaduais. No entanto, trata-se de um critério "contaminado" por influências políticas e econômicas em virtude dos textos serem simplesmente uma reprodução de releases das prefeituras e do governo estadual. Tal situação vai ao encontro do que Shoemaker e Reese (1996 apud SILVA, 2014b) defendem a respeito do julgamento do que é notícia. Segundo esses autores, a noticiabilidade é perpassada por uma série de influências, dentre elas as extra media, tais como as "influências políticas e culturais (através de fontes e grupos de interesse, por exemplo), regulamentações governamentais e ações de marketing e de relações públicas" (SHOEMAKER; REESE, 1996 apud SILVA, 2014b, p. 126).

$\mathrm{Na}$ sequência do estudo, o noticiário regional do Progresso demonstrou que o critério de entretenimento/curiosidade, em específico o esporte, é um dos mais acionados pelo impresso para noticiar localidades além do território imperatrizense. Nesse ponto, os municípios com times de futebol, equipes ou atletas com participação nos campeonatos estaduais ou mesmo nacionais foram os tipos de notícias responsáveis por trazer os municípios do interior do Maranhão para as páginas do jornal investigado.

\section{Considerações Finais}

Ao buscar identificar os critérios de noticiabilidade presentes nas notícias sobre municípios próximos de Imperatriz (MA), cidade sede do jornal O Progresso, o artigo busca oferecer uma contribuição para os estudos de jornalismo regional por meio da discussão em torno dos parâmetros utilizados pelo jornalismo na cobertura e delimitação de uma região.

Parte-se do reconhecimento de que os jornais, ao publicarem informações sobre certas cidades, estabelecem em suas páginas uma "regionalização". Neste sentido, a análise dos conteúdos jornalísticos do Progresso no período estabelecido revelou a presença de 45 municípios do Maranhão e Tocantins, sendo que as cidades incluídas na área de circulação do veículo tiveram uma baixa presença. Dessa maneira, entendemos que não há uma preocupação do jornal em cobrir as localidades onde ele é comercializado ou possui assinantes.

Além disso, a análise das matérias referentes a localidades do entorno de Imperatriz (MA) revelou que a proximidade é o critério de noticiabilidade mais 
acionado pela produção jornalística para pautar centros urbanos além da sede do jornal. Também constatamos a frequência recorrente dos critérios de justiça e governo nas notícias dos lugares mais distantes de Imperatriz. Enquanto que a proximidade, sobretudo geográfica, aparecia nas matérias das cidades próximas ao território imperatrizense, tanto do Maranhão como Tocantins.

A análise demonstrou ainda uma contaminação do critério de governo por influências políticas e econômicas. Consideramos que essa situação pode ser fruto da presença de releases das prefeituras municipais e do governo estadual publicada nas páginas do impresso. Essa questão merece um estudo mais aprofundado no âmbito das rotinas produtivas, de modo a compreender como os jornalistas julgam a noticiabilidade de um evento.

Além desses, localizamos nas matérias analisadas a presença dos critérios de entretenimento/curiosidade, proeminência, impacto, tragédia/drama, polêmica e conflito. Eles apareceram de forma isolada ou combinada nas notícias, demonstrando assim que o julgamento do que é notícia é uma construção cognitiva acionada por diferentes fatores.

Evidencia-se ainda que a cobertura regional do Progresso não envolve atores da sociedade civil ou de grupos destituídos de poder político ou econômico, assim como não abre espaço para os interesses e aspirações das cidades. Assim, os acontecimentos regionais acabam assumindo o status de notícias apenas quando agregam oficialismo, violência ou entretenimento.

Finalmente, assinalamos que a investigação preliminar aponta caminhos importantes, a partir da geografia, para uma reflexão sobre o jornalismo praticado fora das metrópoles. A presença dos jornais instalados em cidades com uma centralidade urbana, como é o das cidades médias, possibilita repensar a configuração do jornalismo regional, olhando para as empresas jornalísticas não de forma isolada em seus municípios sedes, mas inseridas em contextos mais abrangentes de produção de conteúdo, presença e captação de receitas.

\section{REFERÊNCIAS}

AGUIAR, Sonia. Territórios do jornalismo: Geografias da mídia local e regional no Brasil. Petrópolis: Vozes, 2016.

ALSINA, Rodrigo MIQUEL. A construção da notícia. Petrópolis: Vozes, 2009.

ALVES, Andreza Galiego Leopoldino; CUNHA, Hercules Farnesi. Os jornais impressos do interior: o financiamento de releases e a credibilidade. Conexão Eletrônica, v. 11, n. 01, 2014. Disponível em: http://revistaconexao.aems.edu.br/edicoes-anteriores/2014/ciencias-sociais-aplicadas-e-ciencias-humanas-3/. Acesso em: 20 de janeiro de 2018.

ASSIS, Francisco de. Por uma geografia da produção jornalística: a imprensa do interior. In: Anais do XXXVI Congresso Brasileiro de Ciências da Comunicação. Manaus: Intercom, 2013. Disponível em: http://www.intercom.org.br/papers/nacionais/2013/resumos/R8-0810-2.pdf. Acesso em: 20 dez 2017.

BUENO, Wilson da Costa. Jornal do Interior: conceitos e preconceitos. In: ASSIS, Francisco de (Org.). Imprensa no interior: conceitos e contextos. Chapecó: Argos Editora Unochapecó, 2013.

CAMPONEZ, Carlos. Jornalismo Regional: proximidade e distanciações. Linhas de reflexão sobre uma ética da proximidade do jornalismo. In: CORREIA, João Carlos (Org.). Ágora Jornalismo de proximidade: limites, desafios e oportunidades. Covilhã: LabCom, 2012. 
DEOLINDO, Jacqueline da Silva. Regiões jornalísticas: uma abordagem locacional e econômica da mídia do interior fluminense. Tese (doutorado). 361f. Universidade Estadual do Rio de Janeiro (UERJ), Rio de Janeiro, 2016.

Cidade e indústrias de mídia: distinções entre metrópole e interior. In: Anais do XIII Simpósio Nacional de Geografia Urbana. Rio de Janeiro: UERJ, 2013.

DORNELLES, Beatriz. Jornalismo comunitário em cidades do interior: uma radiografia das empresas jornalísticas: administração, comercialização, edição e opinião dos leitores. Porto Alegre: Sagra Suzzato, 2004.

Localismo nos jornais do interior. Famecos, v. 17, n. 03, 2010. Disponível em: http://revistaseletronicas.pucrs.br/ojs/index.php/revistafamecos/article/view/8191. Acesso em: 9 jan 2018.

FADUL, Anamaria; GOBBI, Maria Cristina. Mídia e região na era digital: diversidade cultural, convergência midiática. São Paulo: Arte \& Ciência, 2006.

FERNANDES, Mario Luiz. A proximidade como valor-notícia na imprensa do interior. In: ASSIS, Francisco de (Org.). Imprensa do interior: conceitos e contextos. Chapecó: Argos Editora Unochapecó, 2013.

FRANCISCATO, Carlos Eduardo. Limites teóricos e metodológicos nos estudos sobre a noticiabilidade. In: SILVA, Gislene; SILVA, Marcos Paulo da; FERNANDES, Mario Luiz (Orgs.). Critérios de noticiabilidade: problemas conceituais e aplicações. Florianópolis: Insular, 2014.

GADINI, Sérgio Luís; SCHOENHERR, Rafael. Estratégias regionais de produção jornalística: uma proposta ao estudo de casos de mídia impressa no Paraná. Eptic, v. 18, n. $03,2016$. Disponível em: https://seer.ufs.br/index.php/eptic/article/view/5802 Acesso: 14 dez 2017.

HERSCOVITZ, Heloísa. Análise de Conteúdo em Jornalismo. In: LAGO, Cláudia; BENETTI, Marcia. Metodologia da Pesquisa em Jornalismo. Petrópolis: Vozes, 2008.

MCCOMBS, Maxwell. A teoria da agenda: a mídia e a opinião pública. Rio de Janeiro: Vozes, 2009.

O PROGRESSO. Homem é encontrado Morto em Araguaína. Jornal O Progresso, Imperatriz, 10 de out. 2017, C2, p.2.

Criada a Associação Comercial de Governador Edson Lobão. Jornal O Progresso, Imperatriz, 06 de out. 2017, C2, p.7.

Ex-prefeita de Bom Jardim é presa pela polícia civil em São Luís. Jornal O Progresso, Imperatriz, 25 de out. 2017, C1, p.7.

SANTOS, Milton. Classificação funcional dos jornais brasileiros - As regiões jornalísticas (1955). Noticiários da Rede Alcar. ano 7, n. 83, nov. 2007.

SILVA, Gislene. Para pensar os critérios de noticiabilidade. In: SILVA, Gislene; SILVA, Marcos Paulo da; FERNANDES, Mario Luiz (Orgs.). Critérios de noticiabilidade: problemas conceituais e aplicações. Florianópolis: Insular, 2014a.

SILVA, Marcos Paulo da. A significância social como dimensão da noticiabilidade. In: SILVA, Gislene; SILVA, Marcos Paulo da; FERNANDES, Mario Luiz (Orgs.). Critérios de noticiabilidade: problemas conceituais e aplicações. Florianópolis: Insular, 2014b.

TRAQUINA, Nelson. Teorias do Jornalismo: a tribo jornalística - uma comunidade interpretativa. Florianópolis: Insular, 2008. 